\title{
A CS1 Spatial Skills Intervention and the Impact on Introductory Programming Abilities
}

\author{
Ryan Bockmon \\ University of Nebraska - Lincoln \\ Lincoln, Nebraska \\ rbockmon@cse.unl.edu \\ Jonathan Gratch \\ Texas Woman's University \\ Denton, Texas \\ jgratch@twu.edu
}

\author{
Stephen Cooper \\ University of Nebraska - Lincoln \\ Lincoln, Nebraska \\ scooper22@unl.edu \\ Sheryl Sorby \\ University of Cincinnati \\ Cincinnati, Ohio \\ sheryl.sorby@uc.edu
}

\author{
William Koperski \\ University of Nebraska - Lincoln \\ Lincoln, Nebraska \\ wijakoperski@huskers.unl.edu \\ Mohsen Dorodchi \\ University of North Carolina at \\ Charlotte \\ Charlotte, North Carolina \\ mdorodch@uncc.edu
}

\begin{abstract}
This paper discusses the results of replicating and extending a study performed by Cooper et al. examining the relationship between students' spatial skills and their success in learning to program. Whereas Cooper et al. worked with high school students participating in a summer program, we worked with college students taking an introductory computing course. Like Cooper et al.'s study, we saw a correlation between a student's spatial skills and their success in learning computing. More significantly, we saw that after applying an intervention to teach spatial skills, students demonstrated improved performance both on a standard spatial skills assessment as well as on a CS content instrument. We also saw a correlation between students' enjoyment in computing and improved performance both on a standard spatial skills assessment and on a CS content instrument, a result not observed by Cooper et al.
\end{abstract}

\section{CCS CONCEPTS}

- Social and Professional topics $\rightarrow$ CS1;

\section{KEYWORDS}

CS1; Intervention; Replication; Spatial Skills; Attitudes

\section{ACM Reference Format:}

Ryan Bockmon, Stephen Cooper, William Koperski, Jonathan Gratch, Sheryl Sorby, and Mohsen Dorodchi. 2020. A CS1 Spatial Skills Intervention and the Impact on Introductory Programming Abilities. In The 51st ACM Technical Symposium on Computer Science Education (SIGCSE '20), March 11-14, 2020, Portland, OR, USA. ACM, New York, NY, USA, 7 pages. https://doi.org/10. $1145 / 3328778.3366829$

Permission to make digital or hard copies of all or part of this work for personal or classroom use is granted without fee provided that copies are not made or distributed for profit or commercial advantage and that copies bear this notice and the full citation on the first page. Copyrights for components of this work owned by others than the author(s) must be honored. Abstracting with credit is permitted. To copy otherwise, or republish, to post on servers or to redistribute to lists, requires prior specific permission and/or a fee. Request permissions from permissions@acm.org.

SIGCSE '20, March 11-14, 2020, Portland, OR, USA

(C) 2020 Copyright held by the owner/author(s). Publication rights licensed to the Association for Computing Machinery.

ACM ISBN 978-1-4503-6793-6/20/03...\$15.00

https://doi.org/10.1145/3328778.3366829

\section{INTRODUCTION}

Spatial skills/spatial ability research dates back to the 1800's when Sir Frances Galton focused on discovering how people differ in their "mental disposition" through the use of mental imagery [19]. Since then, researchers have explored what factors make up a person's spatial skills. Much more recently, in 1974, Guilford and Lacy identified two major factors within spatial skills; spatial visualization and spatial orientation [21]. In 1979, Lohman stated that the ability to perform mental rotations on an object defined an important aspect of a person's spatial abilities [29]. Other researchers have identified different spatial skills, including paper folding, map reading/way-finding, and embedded figures. This paper focuses on mental rotations, as it is the most heavily studied spatial skill with regards to programming achievement.

Spatial skills have been shown to play an important role in student performance across STEM disciplines [18, 34, 45, 49]. Within STEM, studies have shown that females and those from low socioeconomic status (SES) backgrounds have lower spatial abilities $[8,26]$; and not surprisingly, they are underrepresented in many STEM disciplines. Fortunately, students can be taught how to improve their spatial skills, which has been linked to improved retention within many STEM majors [44, 45]. There have been several studies within computer science classrooms suggesting that there is a link between a student's spatial abilities and the student's ability to learn to program $[10,17,24,25,37,53]$.

This paper discuses our attempt to replicate one of those studies, by Cooper et al. [10]. We pose the following research questions to frame our work:

(1) Is there a correlation between a student's spatial skills and their success in learning to program?

(2) Can spatial skills successfully be taught to students taking introductory computing classes, and do students who learn spatial skills also demonstrate improved performance in computing?

(3) Do students who have higher enjoyment with computing demonstrate higher performance in computing and spatial skills? 


\section{RELATED RESEARCH}

Spatial skills have been shown to be important in success in many engineering disciplines and in science [7, 40, 41]. Barker found that well developed spatial skills are essential to understand basic and structural chemistry [4]. Carter et al. ran a study with 2,498 students enrolled in the first semester of a college-level general chemistry course where they found that spatial score is most strongly correlated to unit conversion calculations [7]. Sorby found that a person's spatial skills have a correlation between their ability to learn to use computer aided design software [41]. Shea et al. ran a twenty year long longitudinal study with 563 thirteen year old children that scored at the top $0.5 \%$ on the Scholastic Assessment Test Mathematics and Scholastic Assessment Test Verbal, finding that the students' spatial ability was also a good indicator in addition to their SAT-M and SAT-V in predicting educational outcomes over the 20 years [39].

\subsection{Spatial Skills and CS}

It makes sense that spatial skills would be important to engineering and chemistry students. Engineering and chemistry students typically deal with 2-D and 3-D objects and shapes regularly in their schooling. It is less clear that there should be any correlation between spatial skills and students' programming achievement. In 1984, Webb ran a study with 35 students and found that students' spatial ability was the best predictor of knowledge of basic commands after learning Logo for one week [53]. In 1986, Mayer et al. ran a study with 57 college students in a course in Basic and found that logical reasoning and spatial abilities were the primary cause of success in learning Basic [31]. Vicent et al. found that a person's spatial skill level was the most significant predictor of success in their ability to interact with and take advantage of the computer interface in performing database manipulations [51]. Norman proposed models for how individual differences are expected to affect performance when technology is introduced stating that, "the primary cognitive factor driving differences in performance using computer-based technology is spatial visitation" [33]. Cox looked into a student's ability to navigate source code and the creation of their codespace or "mental model of source-code structure" [11].

Fisher et al. explored how sex differences linked to spatial cognition and codespace [18]. Fisher et al. also found that not only are there gender differences in spatial skills, but gender plays a role in how a person navigates source code. Males tend to use a top down development/comprehension strategy while females tend to use route-based bottom-up development/comprehension strategies [18].

Fincher ran a study with 177 participants from eleven postsecondary educational institutions and found a small positive correlation between scores in a spatial visualization task and programming marks, though attributing programming success to higher IQ rather than to spatial skills [17]. Jones and Burnett ran a study with 24 participants finding that participants with high spatial abilities completed code comprehension exercises faster than those with lower spatial abilities, along with a strong relation between spatial ability and results in their programming modules [24]. Jones and Burnett later found a correlation between mental rotation skills and programming success [25]. Most recently Parkinson et al. investigated the relationship between spatial skills and computer science [38] and Parker et al. found that students' spatial skills have a high impact on computer science achievement [37].

\subsection{Factors impacting Spatial Skills}

Studies have looked into what might influence a person's spatial ability. Those studies show that SES, race, and gender all play a role. Levine et al. found that children from lower SES families have lower spatial skills but saw little to no difference in scores based on their gender. At the same time, children from higher SES families have higher spatial skill as well larger gender differences [26]. Casey et al. also found significant differences in spatial skills, favoring students from middle or high SES groups [8]. More recently, Parker et al. studied the effect of SES on computer science achievement [37]. SES impacts both spatial skills and computer science achievement.

Ault and John ran a comparative study at Polytechnic of Namibia in Africa. Their study showed that their students were scoring lower than those in industrialized countries [3]. Another study at a historically black university showed that their students scored significantly lower than the average but after administering material that focused on improving spatial visualization the mean scores of those students were significantly improved [46].

There is evidence to suggest that the 3-D spatial visualization skills of women lag behind those of males. Hier theorizes that the cause of these differences include the belief that spatial ability is related to a male sex hormone [22]. Fennema et al. theorizes that environmental factors are the primary reasons for male-female differences in spatial skill levels [15]. There are conflicting opinions as to whether differences on spatial performance between genders are linked to differences in mathematics performance. Tartre suggests that this may be the case [49], while Fennema and Sherman found that while there were few sex-related cognitive differences in mathematical abilities between males and females, there were differences in spatial visualization abilities between male and female students [15]. Fennema and Sherman's observations were echoed by Lindberg et al. [27], who did a meta-analysis of studies involving a much larger student population.

Gender differences in 3-D spatial skills are likely due to a combination of several factors. Hyde [23] performed a meta-analysis on studies of males and females that occurred. In identifying 30 studies, she notes small but statistically significant differences between the visual-spatial abilities of males and females. Linn and Peterson [28] performed a meta-analysis of studies occurring from 1974-1982. They found large gender differences (with males scoring much higher) on measures of mental rotation. Many other studies note spatial ability differences between males and females, with females having lower spatial abilities. While there is a difference of opinion between whether these differences appear prior to or after puberty (for example, Maccoby and Jacklin [30] provide evidence of differences appearing in adolescence while Newcombe et al. [32] suggest male-female differences exist prior to adolescence), all of these studies do confirm differences by the time students become adolescents. 


\subsection{Teaching Spatial Skills}

Studies have shown that spatial skills can be learned by activities outside of academia, such as playing video games [47], participating in sports [35], and other leisure activities [9]. Studies have shown that spatial skills can be learned in a class setting. In 1993, Sorby et al. [44, 45] conducted a pilot study course for improving spatial skills for engineering students. Results from their pilot study were promising. In a longitudinal study conducted in 2000 [42], Sorby found that for students who initially demonstrated poorly developed spatial skills, enrollment in a spatial skills course improved their success in graphics courses by a half-letter grade, and improved retention in their engineering majors. Sorby found that the retention rates for females that participated in a spatial visualization course significantly increased [42].

Field evaluated a course that ran from 1995-1998 that was created to teach students mental cutting spatial visualization [16]. In 2001, Gerson et al. developed a multimedia software and a workbook for the improvement of 3-D spatial visualization skills for engineering students [20]. Veurink and Sorby ran a longitudinal study at Michigan Technological University. They analyzed 15 years of data from a spatial training course. The course targeted students who scored below $60 \%$ on the Purdue Spatial Visualization Test: Rotations (PSVT:R). Veurink and Sorby found that students taking the course continued with STEM-related courses at a greater rate than their counterparts who did not complete the training. They also found that students who completed the training often times outperformed students who initially had slightly stronger spatial skills but did not take the course [50].

\subsection{Replicating a Study}

While there are studies exploring the relationship between spatial skills and student performance in computing, little has been done to teach spatial skills to computing students. During the summer of 2014, Cooper et al. ran a two week summer coding workshop to explore the relations between spatial skills and their students' achievement in learning to program. The workshop was conducted over a two week session for two groups of rising twelfth grade student programmers. One group had a 45 minute spatial skill training in the mornings along with the normal material, replacing a review of the previous day's material. Not only did Cooper et al. find that there is a correlation between students' spatial skill and their performance in taking a subset of the AP CS exam, they also concluded that the treatment group scored better on the subset of the AP CS exam as well as had higher confidence with respect to their perceived programming experience [10]. This paper discuses our attempt to replicate Cooper et al.'s results with in an introductory computing course at the collegiate level.

\section{METHODS}

In this study, we targeted students who were enrolled in a introductory computer science course at three universities; the University of Nebraska - Lincoln (UNL), Texas Woman's University and University of North Carolina at Charlotte. Data was collected across multiple sections of CS1. Each section was taught in a different programming language: Java, C, Python and Matlab. Thinking it would be unfair to split sections between control and treatment group, we instead ran our study over two years. In year one, we collected control data to see if there was a correlation between students' spatial skills and their programming achievement durning the fall semester of 2017 and spring semester of 2018. All data was collected using a pre-post format, where students completed the same assessment instruments both at the start and at the end of the course. In year two, we collected treatment data by collecting pre-post data while running our spatial skills intervention during the fall semester of 2018 and spring semester of 2019.

Professors did not want to overload their students with extra required material, so all participation was voluntary, with incentives used to encourage students to participate. All incentives were approved by the university's IRB process and consisted of a $\$ 10$ gift card and/or extra credit depending on what the instructor offered. We note that because participation in the study was voluntary, there is a chance of having participation bias in our results. However there has been little research done on the impact of students' spatial skills in computing and any positive results will help encourage further research.

\subsection{Student Population}

The control group consisted of 274 participants and the treatment group consisted of 71 participants. There was a total of 175 males and 95 females in the control group and a total of 43 males and 28 females in the treatment group. We expect that the significant decrease in participants between the two groups was because the treatment group had significantly more work to do than the control group.

\subsection{Instrument Design}

Four instruments were used to collect data. The first instrument collected basic demographic data on a student: age, gender, race and SES. The second instrument used was the Revised Purdue Spatial Visualization Test (PSVT:R) [55]. The PSVT:R consists of 30 questions that present two 3-D objects depicted in 2-D. The first object is an example; that is, it depicts a before and after image of an object as rotations are applied. The second is shown as a before, with five possible outcomes of the object after applying the same rotation as the example object [55]. The third instrument used was a validated revised version of Parker's et al.'s Second Computer Science 1 Exam (SCS1) [36]. We have titled this exam SCS1R. The SCS1R consists of nine questions covering topics commonly taught in a first year computer science course. Each question is designed to be answerable across different multiple programming languages [5]. The fourth survey used was a modified version Dorn and Tew's Computing Attitude Survey version 4 (CASv4) [14]. It was modified by adding some gender-focused questions from Wiebe's survey [54]. The completed survey consisted of 40, 5-point likert scale questions to probe students' attitudes towards computation [6].

\subsection{Intervention Design}

Following what Cooper et al. did in their study, we created eight modules that would be taught during the semester. In contrast with Cooper et al., we provided instruction online rather than face-toface, to keep material consistent across all sections. We chose to use a hybrid approach, a combination of online video lectures and 
worksheets. Each module consisted of one online video lecture that we created, at least one example video, a link to online practice, and a printable worksheet. Each video was kept under 8 minutes in length to keep students engaged. The online practice was created by Sorby [1] and consisted of examples and practice questions. The worksheets consisted of 3-4 pages of multiple choice and hand drawing questions. Students had one to two weeks to complete and turn in each worksheet. The modules consisted of:

- Module 1 - Surfaces and solids of revolution - These shapes are "created by revolving a set of 2-D curves about a coordinate axis" [43]

- Module 2 - Isometric drawings - These drawings depict a 3-D object on a 2-D sheet of paper. An isometric view is the view looking down a diagonal of a cube that is part of the object.

- Module 3 - Coded plans - These drawings depict a top-down view of an isometric shape, where they each "cube" is numbered by the height of the isometric shape.

- Module 4 \& 5 - Orthographic drawings - These drawings depict "the faces of the object straight on or parallel to the viewing plane," including top, side, and front views [43].

- Module 6 - Rotations about a single axis - This transformation includes turning an object about a straight line, or axis of rotation.

- Module 7 - Rotations about two or more axes - This transformation includes turning an object about multiple straight lines, or axes of rotation.

- Module 8 - Reflections and symmetry - The reflection transformation happens when an object is reflected across an entire plane. An object is symmetrical if a plane can cut the object into two halves that are mirror images of each other.

\subsection{Analysis}

To test whether there was correlation between students' spatial skills and their ability to program we used a Pearson's r. The value of the correlation coefficient varies between +1 and -1 . An absolute value closer to 1 indicates a high degree of association between the two variables. As the correlation coefficient value goes towards 0 , the relationship between the two variables will be weaker [2].

To test whether we successfully improved both students' spatial skills and programming ability we used a t-test if the data was normally distributed. If the data was not normally distributed we used a non-parametric Kruskal-Wallis or a non-parametric oneway analysis of variance test (ANOVA) with associated p-value to determine the significance of the results [52]. A D'Agostino and Pearson's test was used to test for normal distribution. The test combines skew and kurtosis to produce an omnibus test of normality [12]. Throughout this paper, we used a p-value of less than 0.01 to indicate that the results found are significant.

\section{RESULTS}

\subsection{Spatial Skills/Programming Correlations}

The first step in our study was to confirm whether or not there is a correlation between students' spatial skills and their success in learning to program. After running a Pearson's $r$ we observed that

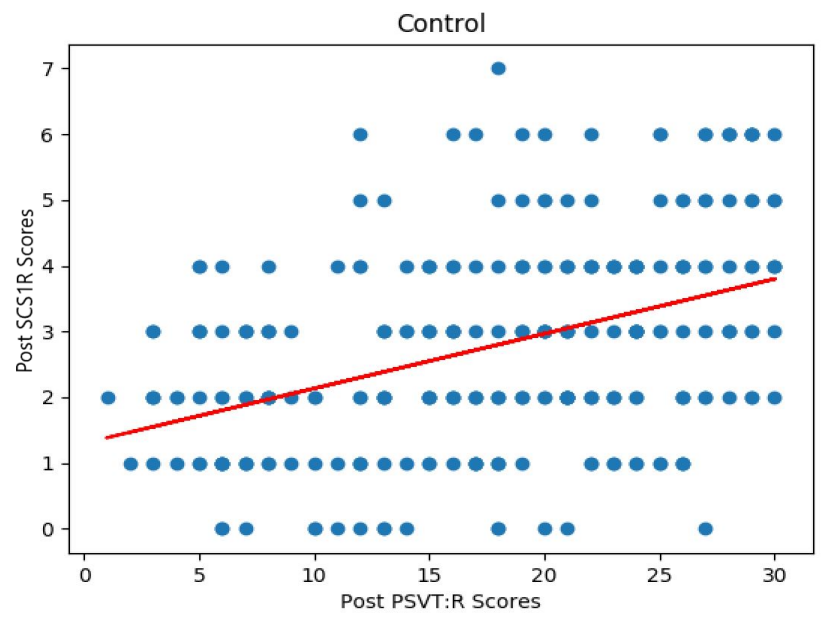

Figure 1: Control Post PSVT:R - Post SCS1R Correlation $(r=$ 0.41 , p-value $<0.01$ )

Table 1: Spatial - Control Vs Treatment

\begin{tabular}{llll} 
& $\begin{array}{l}\text { Control } \\
\mu_{c}\left(\sigma_{c}\right)\end{array}$ & $\begin{array}{l}\text { Treatment } \\
\mu_{t}\left(\sigma_{t}\right)\end{array}$ & $\mathrm{p}$-value \\
\hline Pre-PSVT:R & $19.2(6.8)$ & $19.9(6.8)$ & 0.46 \\
Post-PSVT:R & $17.7(6.5)$ & $21.1(6.7)$ & $<0.01$ \\
\hline$\triangle$ PSVT:R & $-1.5(5.8)$ & $1.2(3.5)$ & $<0.01$ \\
\hline
\end{tabular}

there is a correlation between how well students scored on the prePSVT:R and post-SCS1R $(r=0.31$, p-value $<0.01)$. We also observe that there is a correlation between post-PSVT:R and post-SCS1R $(r=0.41$ and a p-value $<0.01)$ as shown in Figure 1. Both results confirming what Cooper et al. found in their study [10].

These results indicate that not only is there a correlation between students' spatial skills and how well they did on the SCS1R, but students' spatial skills towards the end of the semester have a stronger correlation to how well they do on the SCS1R. In other words, students are not confined to what spatial skills they inherently have prior to taking the introductory computing course. Thus, there is a chance to run a intervention during the semester to help improve students' spatial skills and hopefully improve their programming skills as well.

\subsection{PSVT:R Performance}

As we used an intervention to target students' spatial skills we expected to see that their spatial skills increased over the semester. We did so by testing whether or not the treatment group had a significant increase in spatial skills compared to the control group. Running a normality test, we determined that both the treatment and control groups PSVT:R scores are normally distributed, and we used a t-test to determine if there is significant difference between the two groups. Table 1 shows the mean $(\mu)$ and standard deviation $(\sigma)$ of both the control and treatment group scores for the PSVT:R.

There was no statistically significant difference between the control group and treatment group on the pre-PSVT:R $\left(\mu_{c}=19.2, \sigma_{c}=\right.$ 
Table 2: Content - Control Vs Treatment

\begin{tabular}{llll}
\hline & $\begin{array}{l}\text { Control } \\
\mu_{c}\left(r^{2} k_{c}\right)\end{array}$ & $\begin{array}{l}\text { Treatment } \\
\mu_{t}\left(\text { rank }_{t}\right)\end{array}$ & $\mathrm{p}$-value \\
\hline Pre-SCS1R & $1.7(169)$ & $1.9(187)$ & 0.15 \\
Post-SCS1R & $2.8(163)$ & $3.5(209)$ & $<0.01$ \\
\hline$\triangle$ SCS1R & $1.1(166)$ & $1.6(199)$ & 0.01 \\
\hline
\end{tabular}

6.8, $\left.\mu_{t}=19.9, \sigma_{t}=6.8, \mathrm{p}=0.46\right)$. This result indicates that both the control and treatment group had similar spatial skills prior to taking an introductory computing course. As for the post-PSVT:R there was a significant difference between the control group and treatment group $\left(\mu_{c}=17.7, \sigma_{c}=6.5, \mu_{t}=21.1, \sigma_{t}=6.7, \mathrm{p}<0.01\right)$. There was also a significant difference between the control group and treatment group in the total difference gained between the preand post-PSVT:R $\left(\Delta_{c}=-1.5, \sigma_{c}=5.8, \Delta_{t}=1.2, \sigma_{t}=3.5, \mathrm{p}<0.01\right)$. These results imply that running our spatial skill intervention did improve students' spatial skills.

\subsection{SCS1R Performance}

Our second research question asks whether running a spatial skills intervention can lead to improved performance on the SCS1R. Running a normality test, we determined that the SCS1R scores for both the treatment and control groups were not normally distributed. Since the data was not normally distributed, we used a non-parametric Kruskal-Wallis test to determine if there was a significant difference between the control group and the treatment group. Kruskal-Wallis takes raw scores and ranks them from lowest to highest. In our case, scores varied between 1 and 341. Table 2 shows the raw score averages $(\mu)$ and rank score averages (rank) of both the control and treatment group scores for the SCS1R.

There was no statistically significant difference between the control group and treatment group on the pre-SCS1R $\left(\mu_{c}=1.7\right.$, $\left.\operatorname{rank}_{c}=169, \mu_{t}=1.9, \operatorname{rank}_{t}=187, \mathrm{p}=0.15\right)$. As for the post-SCS1R there was a significant difference between the control group and treatment group $\left(\mu_{c}=2.8, \operatorname{rank}_{c}=163, \mu_{t}=3.5, \operatorname{rank}_{t}=209, \mathrm{p}\right.$ $<0.01)$. There was also a statistically significant difference between the control group and treatment group in the total score gained from the pre- to post-SCS1R performance $\left(\Delta_{c}=1.1, \operatorname{rank}_{c}=166\right.$, $\left.\Delta_{t}=1.6, \operatorname{rank}_{t}=199, \mathrm{p}=0.01\right)$, as seen in Figure 2. These results imply that students who participated in a spatial skills intervention showed improved SCS1R scores. Results found are similar to those found in Cooper et al.'s study.

\subsection{CS-Enjoyment}

Having an understanding how students' attitudes correlate with their spatial skills can give us a better understanding as to why spatial skills play an important role in computing. Due to challenges in understanding how attitudes play a role in affecting students' abilities, we chose to only look at one of the six attitudinal factors in our survey, CS-Enjoyment. We expect to further explore the relationships between spatial skills and performance in introductory computing in future work. We used a non-refined sum score-above a factor loading of a .32 to score students on each of the 6 attitude

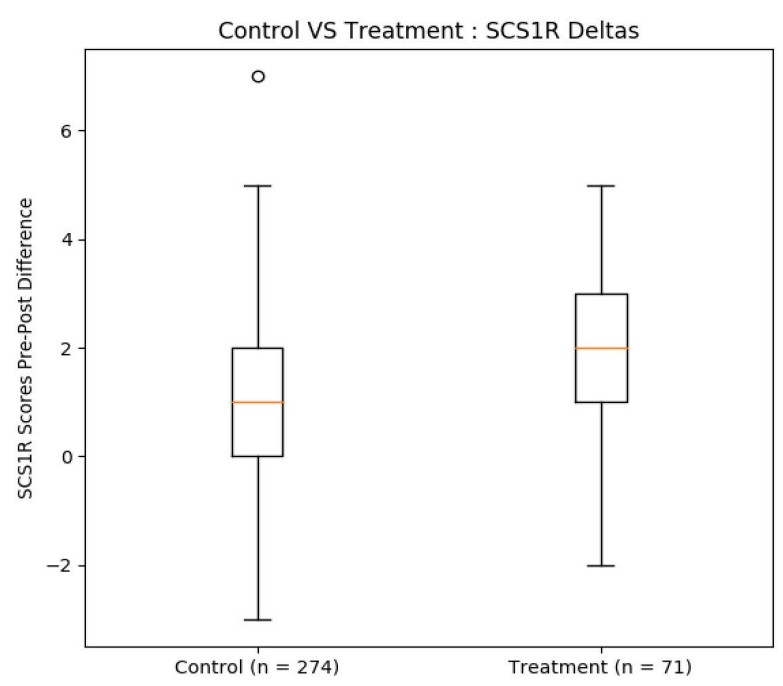

Figure 2: SCS1R Deltas

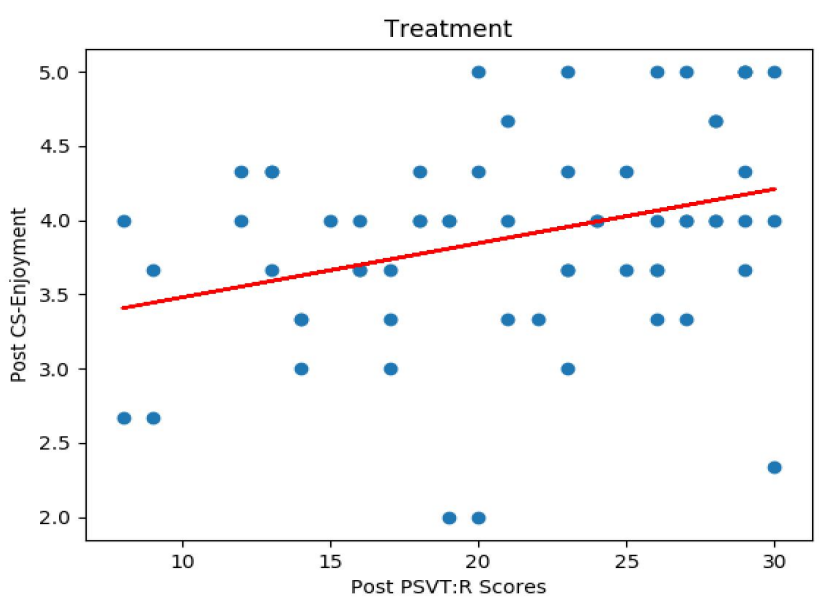

Figure 3: Treatment Post PSVT:R - Post CS-Enjoyment Correlation $(r=0.32$, p-value $<0.01)$

factors [13]. Using a non-refined approach is generally acceptable for most exploratory research situations [48]. Students' attitude scores range from 1 to 5 , where 1 is strongly disagree, 3 is neutral and 5 is strongly agree.

Running a Pearson's $r$, we observed that there is a slight positive correlation between the control groups' post spatial skills and post CS-Enjoyment $(\mathrm{r}=0.22$, $\mathrm{p}$-value $<0.01)$. We also observed a slightly higher positive correlation between the treatment groups' post spatial and post cs-enjoyment $(\mathrm{r}=0.32$, $\mathrm{p}$-value $<0.01)$ as shown in Figure 3. These results show that students who had higher spatial skills also had increased cs-enjoyment in both the control and treatment groups. There are at least two possibilities: 1) students who have higher spatial skills find more enjoyment in computing or 2) students who enjoy computing more develop higher spatial skills. 


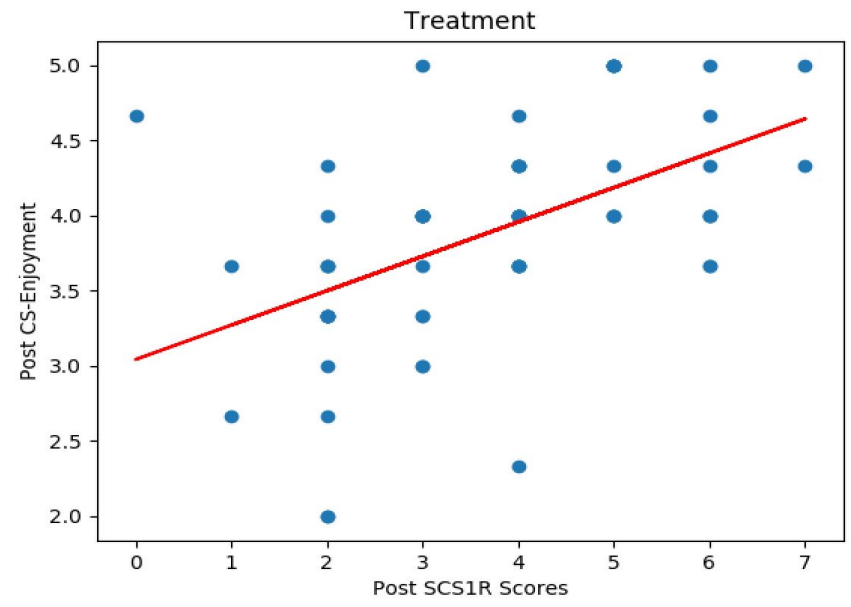

Figure 4: Treatment Post SCS1R - Post CS-Enjoyment Correlation $(r=0.51, \mathbf{p}$-value $<0.01)$

We observed that there is a slight positive correlation between the control group's post-SCS1R grade and post CS-Enjoyment $(r=$ 0.24 , p-value $<0.01$ ). We also observed significantly higher positive correlations between the treatment group's post-SCS1R grade and post cs-enjoyment $(\mathrm{r}=0.51, \mathrm{p}$-value $<0.01)$ as seen in Figure 4 . These results show that students who had higher programming abilities have higher enjoyment with computing. One could argue that enjoying CS gives you more motivation to do better, but there is also some truth that already being good at something can make you enjoy it more too.

These results are interesting. Presently, they are just correlations and further analysis should be conducted to understand how and why these correlations exist.

\section{DISCUSSIONS}

Similar results to Cooper et al.[10] were obtained. Like Cooper et al., our study confirmed that there is a correlation between students' spatial skills and their ability to program. We also observed that over a course of a semester, students' spatial skills towards the end of the semester have a stronger correlation to their programming abilities than their spatial skills prior to taking in an introductory computing course (pre $r=0.31$, post $r=0.41$ ). This provides evidence for the correlation between spatial skills and computing aptitude. Our results also show that without a spatial skills intervention, students' spatial skills slightly decrease over a semester, results not reported in previous studies.

After running a spatial skills intervention, our results show that both students' spatial skills and programming abilities statistically improved over the course of a semester. These results were observed in Cooper et al.'s shorter duration study.

We also explored the correlations between students' post computing enjoyment and both their spatial skills and programming abilities. Our results show that there is a correlation between students' enjoyment and how well they preform on the PSVT:R and SCS1R. But whether it is effective or affective is still unknown at this time and further analysis should be done.

\section{LIMITATIONS}

Several factors could have impacted the results of our study. The first factor is that our participation was voluntary. This could have lead to participation bias. That is, students who participated in the intervention may have tried harder on the post tests without actually improving there skills. Voluntary participation could have also acted as a filter to identify only those students whit the time and inclination to put large amounts of time into the course. With the results found in this study, we hope that we can convince instructors to allow our intervention to be a mandatory part of their classes.

The second factor is that the instrument we used to test for programming abilities, the SCS1R, is a difficult test. It was challenging to differentiate between students who did not take the study seriously and those who did. From what we found while running the study, we have plans to revise the instrument to increase its reliability.

The last factor was that all surveys/exams where administered online and not in a controlled environment. We also did not set a time limit to how long students had to take the PSVT:R, as it is meant to be taken in a 20 minute time frame.

\section{CONCLUSION}

There is still much to learn about spatial skills and their role in computing. The results from this study are promising. We were able to successfully improve students' spatial skills and computing skills over the course of a semester with the use of a spatial skills intervention. However, because participation in our study was voluntary, we do have concerns that there could be participation bias. Are these results replicable, and will results change when making the intervention a mandatory part of a class? The results that we found in this study should help us convince instructors to make the intervention a mandatory part of their classes.

We are interested in how demographic difference and students' attitudes can impact their programming abilities and spatial skills. We hope to write a follow up paper discussing those topics in more detail. We would also like to be able to answer several related questions: Does running an intervention help with computing retention rates? Is it possible to create programming labs that also teach spatial skills so there would be no need to run an intervention? Other studies have shown that there is a gender gap with spatial skills. Does this gender gap in spatial skills help explain the under representation of females in computing?

Our results both confirms what Cooper et al. found in their study while also providing a crucial step to understanding how spatial skill play a role in introductory computing courses. There is a great deal of future work to be done.

\section{ACKNOWLEDGEMENT}

This material is based upon work partially supported by the $\mathrm{Na}-$ tional Science Foundation under Grant Numbers 1711780, 1711830, and 1712331. Any opinions, findings, and conclusions or recommendations expressed in this material are those of the author(s) and do not necessarily reflect the views of the National Science Foundation. Thank you S. Roscoe and A. Jobbins for insightful feedback and comments on earlier drafts of this paper. 


\section{REFERENCES}

[1] [n. d.]. Sorby's online pratice. https://www.higheredservices.org/HES01/. ([n. d.]). Accessed: April 1, 2017.

[2] P. Ahlgren, B. Jarneving, and P. Rousseau. 2003. Requirements for a correlation similarity measure, with special reference to Pearson's correlation coefficient. Journal of the American Society for Information Science and Technology 54, 6 (2003), $550-560$.

[3] H. Ault and J. Samuel. 2010. Assessing and enhancing visualization skills of engineering students in Africa: a comparative study. Engineering Design Graphics Journal 74, 2 (2010), 12-20.

[4] H-D Barker and T. Engida. 2001. Structural chemistry and spatial ability in different cultures. Chemistry Education: Research and Practice in Europe 2, 3 (2001), 227-239.

[5] R. Bockmon, S. Cooper, J. Gratch, and M. Dorodchi. 2019. (Re)Validating Cognitive Introductory Computing Instruments. Proceedings of the 50th ACM Technical Symposium on Computer Science Education (2019), 552-557.

[6] R. Bockmon, S. Cooper, J. Gratch, J. Zhang, and M. Dorodchi. 2020. Validating a CS attitudes instrument. 51st ACM Technical Symposium on Computer Science Education (SIGCSE'20) (2020).

[7] C. S. Carter, M. A. LaRussa, and G. M. Bodner. 1987. A study of two measures of spatial ability as predictors of success in different levels of general chemistry. Journal of Research in Science Teaching 24 (1987), 645-657.

[8] B. M. Casey, E. Dearing, M. Vasilyeva, C. Ganley, and M. Tine. 2011. Spatial and numerical predictors of measurement performance: The moderating effects of community poverty and gender. Fournal of Educational Psychology 103, 2 (2011), 296-311. https://doi.org/10.1037/a0022516

[9] I. D. Cherney and L. Kamala. 2006. Gender-linked differences in the toys, television shows, computer games, and outdoor activities of 5- to 13-year-old childer. Sex Roles 54 (2006), 717-726.

[10] S. Cooper, K. Wang, I. Maya, and S. Sorby. 2015. Spatial skill training in introductory computing. ICER '15 (2015), 13-20.

[11] A. Cox, M. Fisher, and P. O'Brien. 2005. Theoretical considerations on navigating codespace with spatial cognition. 17th Workshop of the Psychology of Programming Interest Group (2005).

[12] R. D’Agostino and E. S. Pearson. 1973. Tests for departure from normality. Biometrika, 60 (1973), 613-622.

[13] C. DiStefano, M. Zhu, and D. Mindrila. 2009. Understanding and Using Factor Scores: Considerations for the Applied Researcher. Practical Assessment, Research Evalation 14, 20 (2009), 1-11.

[14] B. Dorn and A. Tew. 2015. Empirical validation and application of the computing attitudes survey. Computer Science Education 25, 1 (2015), 1-36.

[15] E. Fennema and J. A. Sherman. 1976. Fennema-Sherman mathematics attitudes scales. Instruments designed to measure attitudes toward the learning of mathematics by females and males. Fournal for research in Mathematics Education 7, 5 (1976), 324-326

[16] B. W. Field. 1999. A course in spatial visualization. Fournal for Geometry and Graphics 3, 2 (1999), 201-209.

[17] S. Fincher, B. Baker, I. Box, Q. Cutts, M. de Raadt, P. Haden, J. Hamer, M. Hamilton, R. Lister, and M. Petre. [n. d.]. Programmed to succeed? A multi-national, multiinstitutional study of introductory programming courses. University of Kent, Computing Laboratory Technical Report 1-05 ([n. d.]).

[18] M. Fisher, A. Cox, and L. Zhao. 2006. Using sex differences to link spatial cognition and program comprehension. In Proceedings of the 22nd IEEE International Conference on Software Maintenance (ICSM) (2006), 289-298.

[19] F. Galton. 1880. Mental Imagery. Fortnightly Rev. 24 (1880), 312-324.

[20] H. B. P. Gerson, S. A. Sorby, A. Wysocki, and B. J. Baartmans. 2001. The development and assessment of multimedia software for improving 3-D spatial visualization skills. Michigan Technological University (2001), 105-113.

[21] J. P. Guilford and J. I. Lacy. 1974. Printed classification tests. AAF, Aviation Psychological Progress Research Report 5 (1974), 312-324.

[22] D. B. Hier and W. F. Jr. Crowley. 21982. Spatial ability in androgen-deficient men. New England fournal of Medicine 306, 20 (21982), 1202-1205.

[23] J. S. Hyde. 1981. How large are cognitive gender differences? A meta-analysis using $w^{2}$ and d. American Psychologist 36, 8 (1981), 892-901.

[24] S. Jones and G. Burnett. 2007. Spatial skills and navigatoin of source code. Proceedings of ITiCSE 2007 (2007), 231-235.

[25] S. Jones and G. Burnett. 2008. Spatial skills and learning to program. Human Technology 4, 1 (2008), 47-61.

[26] S. C. Levine, M. Vasilyeva, S. F. Lourenco, N. S. Newcombe, and J. Huttenlocher 2005. Socioeconomic status modifies the sex difference in spatial skill. Psychological Science. American Psychological Society 16, 11 (2005), 841-845.

[27] S. M. Lindberg, J. S. Hyde, J. L. Petersen, and M. C. Linn. 2010. Emergence and characterization of sex differences in spatial ability: a meta-analysis. Child Development 136, 6 (2010), 1123-1135.

[28] M. C. Linn and A. C. Petersen. 1985. Emergence and characterization of sex differences in spatial ability: a meta-analysis. Child Development 56 (1985), 14791498.
[29] D. F. Lohman. 1879. Spatial abilities: a review and reanalysis of the correlations literature, in aptitude research project. Technical Report No. 8, Aptitude Research Project (1879).

[30] E. E. Maccoby and C. N. Jacklin. 1974. The psychology of sex differences. Vol. 1. Standford Univeristy Press., Standford, CA.

[31] R. E. Mayer, J. L. Dyck, and W. Vilberg. 1986. Learning to program and learning to think: What's the connection? Commun. ACM 29 (1986), 605-610.

[32] N. Newcombe, M. M. Bandura, and D. C. Taylor. 1983. Sex differences in spatial ability and spatial activities. Sex roles 9, 3 (1983), 377-386.

[33] K. Norman. 1994. Spatial visualization-a gateway to computer-based technology. fournal of Special Education Technology 12, 3 (1994), 195-206.

[34] S-R. Ou and A. Reynolds. 2008. Predictors of educational attainment in the Chicago longitudinal study. School Psychology Quarterly 23, 2 (2008), 199-229.

[35] S. Ozel, L. Jacques, and C. Molinaro. 2004. Relation between sport and spatial imagery: comparison of three groups of participants. The fournal of Psychology 138, 1 (2004), 49-63.

[36] M. Parker, M. Guzdial, and S. Engleman. 2016. Replication, validation, and use of a language independent cs1 knowledge assessment. ICER '16 (2016), 93-101.

[37] M. Parker, A. Solomon, B. Pritchett, D. Illingworth, L. Margulieux, and M. Guzdial. 2018. Socioeconomic status and computer science achievement. ICER '18 (2018), 97-105.

[38] J. Parkinson and Q. Cutts. 2018. Investigating the relationship between spatial skills and compute science. ICER '18 (2018), 106-114.

[39] D. L. Shea, D. Lubinski, and P. B. Camilla. 2001. Importance of assessing spatial ability in intellectually talented young adolescents: a 20 -year longitudinal study. Journal of Educational Psychology 93, 3 (2001), 604-614.

[40] I. M. Smith. 1964. Spatial ability-its educational and social significance. London: University of London.

[41] S. A. Sorby. 2000. Spatial abilities and their relationship to effective learning of 3-d modeling software. Engineering Desing Graphics fournal 64, 3 (2000), 30-35.

[42] S. A. Sorby. 2001. A course in spatial visualization and its impact on the retention of female engineering studtents. Fournal of Women and Minorities in Science and Engineering 7 (2001), 153-172.

[43] S. A. Sorby. 2011. Developing spatial thinkoink workbook. Cengage Learning, Boston, MA.

[44] S. A. Sorby and B. J. Baartmans. 1996. A course for the development of 3-D spatial visualization skills. Engineering Design Graphics fournal 60, 1 (1996), 13-20.

[45] S. A. Sorby and B. J. Baartmans. 1999. Developing 3-D Spatial Visualization Skills. Engineering Design Graphics fournal, 63, 2 (1999), 21-32.

[46] N. E. Study. 2006. Assessing and improving the below average visualization abilities of a group of minority engineering and technology students. fournal of Women and Minorities in Science and Engineering 12, 4 (2006), 363-374.

[47] K. Subrahmanyam. 1994. Effect of video game practice on spatial skills in girls and boys. Fournal of Applied Developmental Psychology 15 (1994), 13-32.

[48] B. G. Tabachnick and L. S. Fidell. 2001. Using multivariate statistics (5th ed.). Allyn and Bacon, New York, NY.

[49] L. A. Tartre. 1990. Spatial Skills, gender, and mathematics. Mathematics and Gender (1990), 27-59.

[50] N. L. Veurink and S. A. Sorby. 2011. Raising the bar? Longitudinal study to determine which students would benefit most from spatial training. American Society for Engineering Education (2011), 1-13.

[51] K. J. Vicente, B. C. Hayes, and R. C. Williges. 1987. Assaying and isolating individual differences in searching a hierarchical file system. Human Factors 29 (1987), 117-124.

[52] R. L. Wasserstein and N. A. Lazar. 2016. The ASA's Statement on p-Values: Context, Process, and Purpose. The American Statistician 70, 2 (2016), 129-133.

[53] N. Webb. 1984. Microcomputer learning in small groups: Cognitive requirements and group processes. Fournal of Educational Psychology 76 (1984), 1076-1088.

[54] E. N. Wiebe, L. Williams, K. Yang, and C. Miller. 2003. Computer science attitude survey. Technical Report NCSU CSC TR-2003-1 (2003).

[55] S. Y. Yoon. 2011. Revised Purdue Spatial Visualization Test: Visualization of rotations (Revised PSVT:R) [Psychometric Instrument]. (2011). 